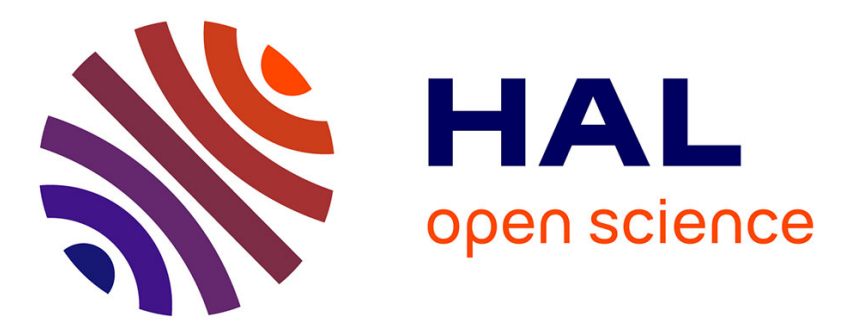

\title{
One strategy for nanoparticle assembly onto 1D, 2D, and 3D polymer micro and nanostructures
}

Ali Issa, Irene Izquierdo, Melissa Merheb, Dandan Ge, Aurelie Broussier, Nawres Ghabri, Sylvie Marguet, Christophe Couteau, Renaud Bachelot, Safi Jradi

\section{To cite this version:}

Ali Issa, Irene Izquierdo, Melissa Merheb, Dandan Ge, Aurelie Broussier, et al.. One strategy for nanoparticle assembly onto 1D, 2D, and 3D polymer micro and nanostructures. ACS Applied Materials \& Interfaces, 2021, 13 (35), pp.41846-41856. 10.1021/acsami.1c03905 . cea-03335135

\section{HAL Id: cea-03335135 \\ https://hal-cea.archives-ouvertes.fr/cea-03335135}

Submitted on 3 Nov 2021

HAL is a multi-disciplinary open access archive for the deposit and dissemination of scientific research documents, whether they are published or not. The documents may come from teaching and research institutions in France or abroad, or from public or private research centers.
L'archive ouverte pluridisciplinaire HAL, est destinée au dépôt et à la diffusion de documents scientifiques de niveau recherche, publiés ou non, émanant des établissements d'enseignement et de recherche français ou étrangers, des laboratoires publics ou privés. 


\section{One strategy for nanoparticle assembly onto 1D, 2D}

\section{and 3D polymer micro and nanostructures}

Ali Issa ${ }^{\dagger}$, , Irene Izquierdo ${ }^{\dagger}$, Melissa Merheb ${ }^{\dagger}, \perp$, Dandan Ge ${ }^{\dagger}$, Aurélie Broussier ${ }^{\dagger}$, Nawres

Ghabrit, Sylvie Marguet, Christophe Couteau ${ }^{\dagger}$, Renaud Bachelot ${ }^{\dagger,}$ and Safi Jradit,*

${ }^{\dagger}$ Light, nanomaterials \& nanotechnologies Laboratory (L2n), Université de Technologie de Troyes \& CNRS ERL7004, 12 rue Marie Curie, 10004 Troyes Cedex, France.

${ }^{\perp}$ Doctoral School of Sciences and Technology, Rafic Hariri Campus, Lebanese University, Hadath 1003, Lebanon.

${ }^{\ddagger}$ NIMBE, CEA, CNRS Université Paris-Saclay, CEA Saclay, F-91191 Gif-sur-Yvette, France.

${ }^{\S}$ Key Lab of Advanced Display and System Application, Ministry of Education, School of Mechatronic Engineering and Automation, Shanghai University, Shanghai, 200072, PR China KEYWORDS: Nanoparticles assembly, Polymer functionalization, 2-photon lithography, 3D assembly, Gold nanoparticles, Quantum dots, Integration of Nano-emitters.

ABSTRACT: The integration of nanoparticles (NPs) into photonic devices and plasmonic sensors requires selective patterning of these NPs with fine control of their size, shape and spatial positioning. In this article, we report on a general strategy to pattern different types of NPs. This strategy involves the functionalization of photopolymers before their patterning by two-photon laser writing to fabricate micro- and nanostructures that selectively attract colloidal 
NPs with suitable ligands, allowing their precise immobilization and organization even within complex 3D structures. Monolayers of NPs without aggregations are obtained and the surface density of NPs on the polymer surface can be controlled by changing either the time of immersion in the colloidal solution or the type of amine molecule chemically grafted on the polymer surface. Different types of NPs (gold, silver, polystyrene, iron oxide, colloidal quantum dots and nanodiamonds) of different sizes are introduced showing a potential towards nanophotonic applications. To validate the great potential of our method, we successfully demonstrate the integration of quantum dots within a gold nanocube with high spatial resolution and nanometer precision. The promise of this hybrid nano-source of light (plasmonic/polymer/QDs) as optical nanoswitch is illustrated through photoluminescence measurements under polarized exciting light.

\section{INTRODUCTION}

Precise organization of nanoparticles (NPs) in multiple dimensions and on continuous length scales would lead to collective properties ${ }^{1,2}$ that differ from those of individual particles, providing high potentials for many applications in plasmonics, ${ }^{3}$ photonics, ${ }^{4,5}$ catalysis, ${ }^{6}$ electronics $^{7}$ and biotechnology. ${ }^{8}$ In that context, Metallic Nanoparticles (MNPs) and Quantum Dots (QDs) attract much attention due to their size tunable optical properties ${ }^{9}$ that have wellestablished applications in numerous fields such as sensing by enhanced Raman ${ }^{10-12}$ and photoluminescence spectroscopy, ${ }^{13}$ biosensing, ${ }^{14}$ bioimaging ${ }^{15,16}$ and integrated quantum photonics. ${ }^{17}$ Notably, patterning these NPs and controlling their spatial positioning at the nanoscale are challenging but highly desirable. Many considerable efforts have been put forth for precise and controllable 1D, 2D and 3D positioning of NPs on substrate surface. ${ }^{18,19}$ This positioning depends on a variety of alternative methods of top-down and bottom-up techniques ${ }^{20}$ including confined space-mediated fluid drying and capillary assembly of nanoparticles onto topographical trap strategies ${ }^{21}$ to form NP linear assemblies. ${ }^{22}$ These methods require a fine 
control of the assembly parameters and a complex setup to fabricate the desired structures. ${ }^{23}$ Focused electron beam irradiation has also been used for the immobilization of twodimensional arrangement of gold nanoparticles (GNPs) that are attached on substrates by chemical methods. ${ }^{24}$ After irradiation, the NPs are fixed on the substrate. However, the chemical attachment of the NPs on the entire substrate makes it difficult to eliminate the unfixed NPs and thus random positioning on the substrate surface will occur. ${ }^{24}$ To improve the assembly of NPs into 3D architectures, microfluidic engineering has been developed. ${ }^{25}$ However, this technique requires a complex sandwich-shaped patterning system, which needs many physical parameters to be adjusted in order to manipulate the microfluid morphology just along the arc of the microfluid path. Other approaches, such as lift-up soft lithography, ${ }^{26}$ polymer single crystals as generic substrates, ${ }^{27}$ micro-contact printing, ${ }^{28}$ direct optical lithography of functional inorganic nanomaterials, ${ }^{29}$ epitaxial growth of DNA-functionalized nanoparticles, ${ }^{30,31}$ electrophoretic deposition ${ }^{32}$ and e-jet printing, ${ }^{33}$ present interesting ways to assemble NPs with the lack of their direct assembly in complex three dimensions unless multiple fabrication steps are used in these techniques.

To the best of our knowledge, the arrangement of NPs of different sizes and natures within complex 3D micro- and nanostructures avoiding the aggregations and unclean substrate surfaces with the capacity to attain the formation of monolayer is still an unsolved challenge. Therefore, development of new general methods involving the three-dimensional arrangement that breaks all the above limitations is strongly needed.

In this article, we present a universal strategy for immobilization of NPs of different natures and sizes on polymer patterns, whatever their size and shape. This new method is based on the chemical grafting of amine molecules on acrylic monomers by Oxa- ${ }^{34}$ or Aza-Michael addition reaction. ${ }^{35-37}$ These reactions involve hydroxyl group, for tertiary amines, or amine group, for primary and secondary amines, to form Oxa or Aza- Michael addition reaction respectively on 
the $\mathrm{C}=\mathrm{C}$ of the acrylate monomers (See supporting information, Figures $\mathrm{S} 1$ and S2). The functionalized acrylate monomer is then used for fabrication of any desired 1D, 2D or 3D computer generated structures on substrate (glass, ITO, silicon) with high resolution using TwoPhoton Polymerization (TPP) lithography. ${ }^{38}$ The TPP lithography is a direct laser writing based on two-photon absorption to achieve photoexcitation of the photoresist in a localized focal volume. ${ }^{39,40}$ After fabrication and development of the sample, the polymer surface presents a high density of amino groups. The obtained polymer templates are then immersed in colloidal NPs resulting in the selective attachment of these NPs on the polymer surface.

\section{RESULTS AND DISCUSSION}

Figure 1-A describes the chemical grafting of tertiary alkanol amines on $\mathrm{C}=\mathrm{C}$ of Pentaerythritol triacrylate (PETA) according to the Oxa-Michael addition reaction. ${ }^{29}$ After fabrication of linear and complex 3D structures by TPP based on femtosecond laser pulses (Figure 1-A), the sample is immersed in a solution of colloidal gold NPs (GNPs) (Figure 1B). During immersion, the negatively charged NPs coming from the carboxyl groups (-COO- $)$ start to assemble, by electrostatic interaction, on the positively charged functionalized polymer surface due to the presence of amine groups (Figure 1-C). The optical microscope images of 3D woodpile structure in Figure 1-D and Figure 1-E show clearly the difference in color before and after immersion of this woodpile in the GNPs solution, which indicates the presence of GNPs after immersion on the polymer surface. The scanning electron microscope (SEM) images of the woodpile surface and "L2n" logo structure in Figures $\mathbf{F}$ and $\mathbf{H}$ confirm the presence of GNPs on the polymer surface after immersion. (For Aza-Michael addition, see supporting information: Figures S3, S4 and S5). 


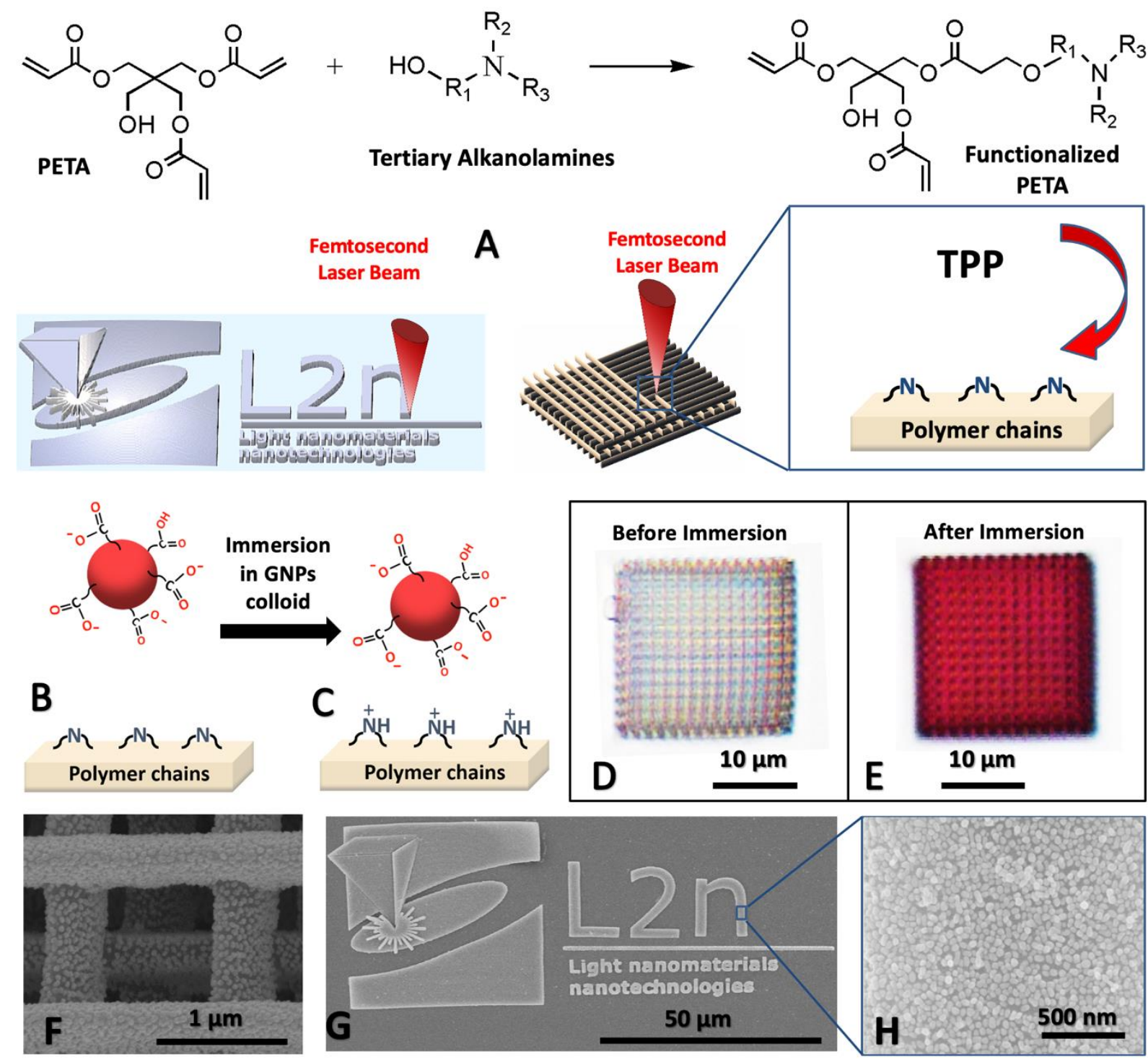

Figure 1. (A) PETA monomer is functionalized by tertiary alkanol amines $\left(\mathrm{R}_{1}=\mathrm{CH}_{3}\right.$, $\mathrm{CH}_{2} \mathrm{CH}_{3} \ldots \mathrm{R}_{2}$ and $\mathrm{R}_{3}=\mathrm{CH}_{3}, \mathrm{CH}_{2} \mathrm{CH}_{3}, \mathrm{CH}_{2} \mathrm{CH}_{2} \mathrm{OH}$...) according to the Oxa-Michael addition reaction, then simple and complex 3D structures were fabricated by TPP of the functionalized monomer based on femtosecond direct laser writing. (B and C) Scheme showing the functional groups on the polymer surface and on the GNPs that leads to their assembly on the polymer surface during immersion in colloidal GNPs (Size $\sim 50 \mathrm{~nm}$ ). Optical microscope images of 3D woodpile structure before (D) and after (E) immersion in GNP colloids. (F) SEM image of the woodpile surface after immersion. (G) SEM image of GNPs assembled on L2n logo structure made by TPP; (H) Zoom on the SEM image shown in $\mathbf{G}$. 
The novelty of this strategy is that different kinds of NPs can be assembled as a monolayer into 1D, 2D and 3D complex microstructures with high selectivity and controlled density, which allows the tuning of their optical properties. This new strategy is applicable for any negatively charged NPs, which is one of the key elements for their selective attachment on polymer surface besides the chemical grafting of amine molecules on acrylate monomers.

The importance of the monomer functionalization is shown in Figure 2-A where the selective attachment of citrate capped GNPs on the functionalized polymer is clearly detected from the SEM image while no attachment of these NPs was observed in the absence of the amine (Figure 2-B).
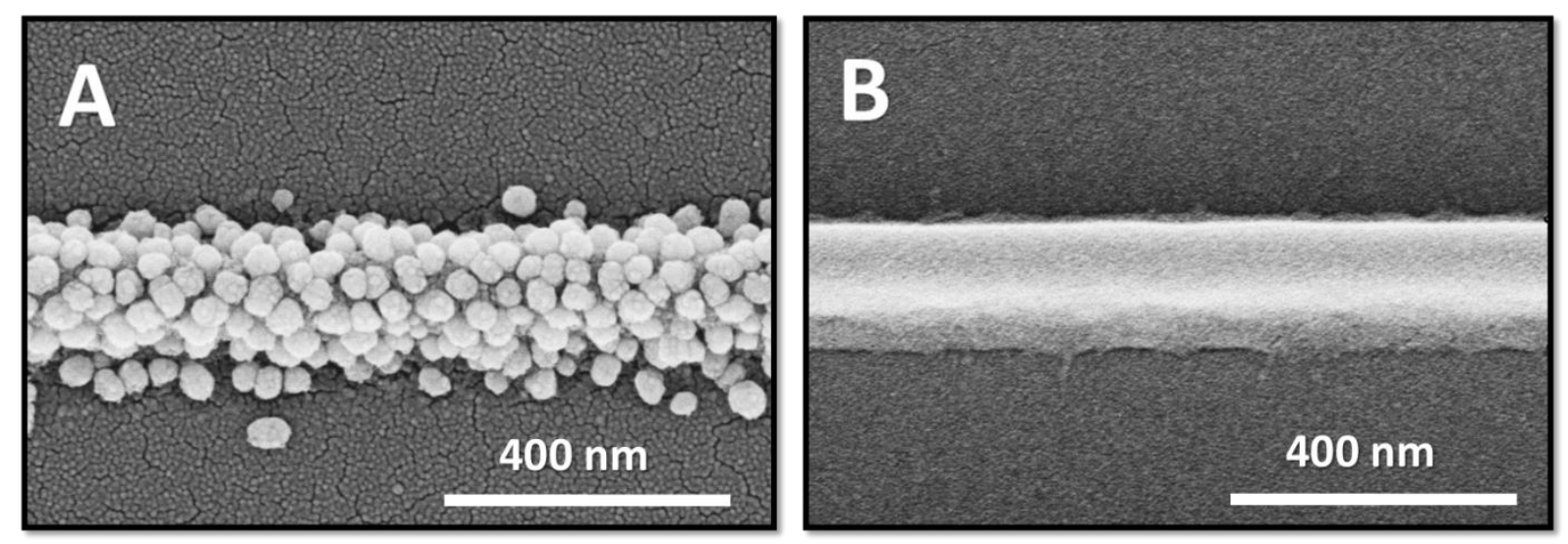

Figure 2. Polymer line fabricated using the functionalized (A) and the non-functionalized (B) photopolymer mixture after immersion in citrate capped GNPs solution for 5 hours.

The assembly of NPs on the polymer surface takes place within the NP colloid, so the time of immersion will affect the GNPs attachment and thus its surface density on the polymer surface. In order to unravel this effect, several experiments are performed on 2D square polymer microstructures. Six samples are prepared and immersed in the GNP solution for specific times, respectively: 1, 10, 30, 120, 300 and 540 minutes, resulting in the formation of well-separated GNP monolayers on the polymer surface. The SEM images in Figure 3 show the surface density of NPs on the polymer surface with the increase of the immersion time. 

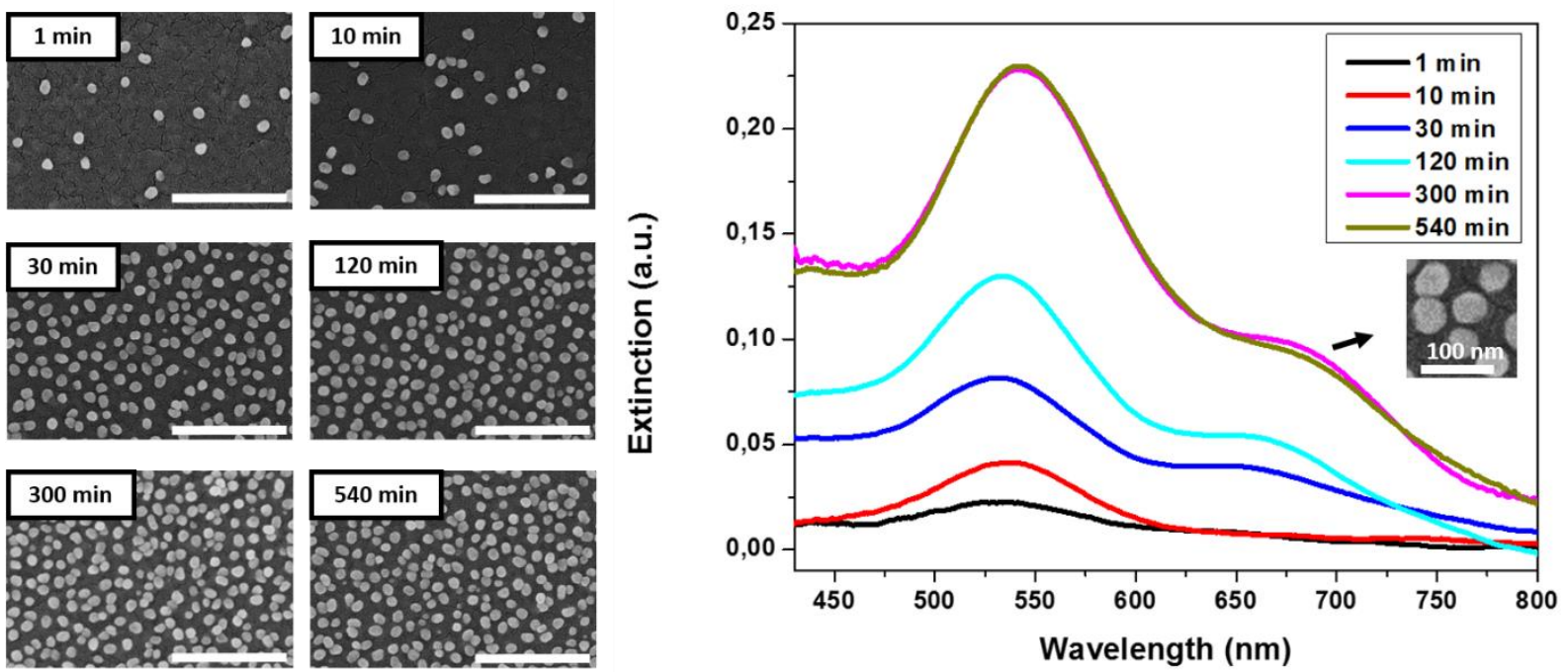

Figure 3. SEM images of 2D immobilization of GNPs on flat microsquare of polymer with different immersion times and their corresponding extinction spectra. Scale bar is $500 \mathrm{~nm}$ on the left side.

It is interesting to note that after only one minute of immersion, there is a significant attachment of GNPs, which indicates the presence of a strong affinity of the GNPs towards the functionalized polymer surface. The surface density of NPs starts to increase with increasing immersion time. Starting from 30 minutes, the corresponding extinction spectra show two distinct maxima. The first band around $\lambda_{\max }=535 \mathrm{~nm}$ is assigned to the dipolar plasmon mode of the individual NPs, while the second red shifted band around $\lambda=680 \mathrm{~nm}$ is attributed to the plasmon coupling between the neighboring particles forming the assemblies. These bands correspond, respectively, to the transverse and longitudinal plasmon modes of the coupled elongated system. ${ }^{41}$

The second band around $\lambda=680 \mathrm{~nm}$ increases as the density increases, indicating of more coupling between GNPs that become closer to each other. ${ }^{41}$ After 300 minutes of immersion, the surface density reaches an equilibrium, which corresponds to the upper limit surface density of $260 \mathrm{NPs} / \mu \mathrm{m}^{2}$ (See Figure S6). 
Consequently, by applying our strategy we are able to control the surface density of NPs on the structured polymer by adjusting the immersion time inside the colloidal solution. Another way to control this surface density is to increase the functionalization rate of amine groups by using a more reactive molecule such as diethanolamine (DEA) which is a secondary amine showing stronger nucleophilic capacity and allowing Aza-Michael addition reaction on the $\mathrm{C}=\mathrm{C}$ bond of the monomer. As a result, the surface density of GNPs shows a drastic increase as compared to the tertiary amine previously used (See Figure S7). To confirm this behavior, the number of accessible amines was quantified using a colorimetric method based on the Orange II (details in Supporting Information). Using this method, the surface density of accessible amines was determined to be $0.6 \pm 0.1 \times 10^{8}$ molecules $\mu \mathrm{m}^{-2}$ for MDEA-functionalized PETA formulation $($ PETA/MDEA molar ratio $=2)$ and $3.4 \pm 0.7 \times 10^{8}$ molecules $\mu \mathrm{m}^{-2}$ for DEAfunctionalized PETA formulation (PETA/DEA molar ratio $=2)($ See orange II amine test supporting information). Several factors discussed in reference ${ }^{38}$ may affect the accuracy of this measurement (surface roughness, the surface swelling, steric hindrance from bound Orange II molecules,...). However, this result is consistent with the behavior observed in Figure S7 and confirms the possibility to increase the density of functional groups using secondary amines instead of tertiary amines.

A uniqueness of this approach is the ability to direct the NP assembly on different shapes and following different dimensions of polymer templates, taking advantage of direct laser writing by TPP which allows writing any 1D, 2D and 3D structures by introducing the numerical script of the desired design in the "Describe" software. ${ }^{42,43}$ As seen in Figure 4, the SEM images show the attachment of GNPs on 3D (Figures 4-A and B), planar (Figure 4-C) and linear (Figure 4-D) structures. The GNP attachment is obtained only on the polymer surface, without any aggregations appearing even within complex 3D microstructures (Figures 4-A and B and Figure S10). At the same time, it is clear that the unstructured substrate is left clean and pristine. 
This confirms the high selectivity of the citrate capped GNPs towards the functionalized polymer surface and the effectiveness of our method.

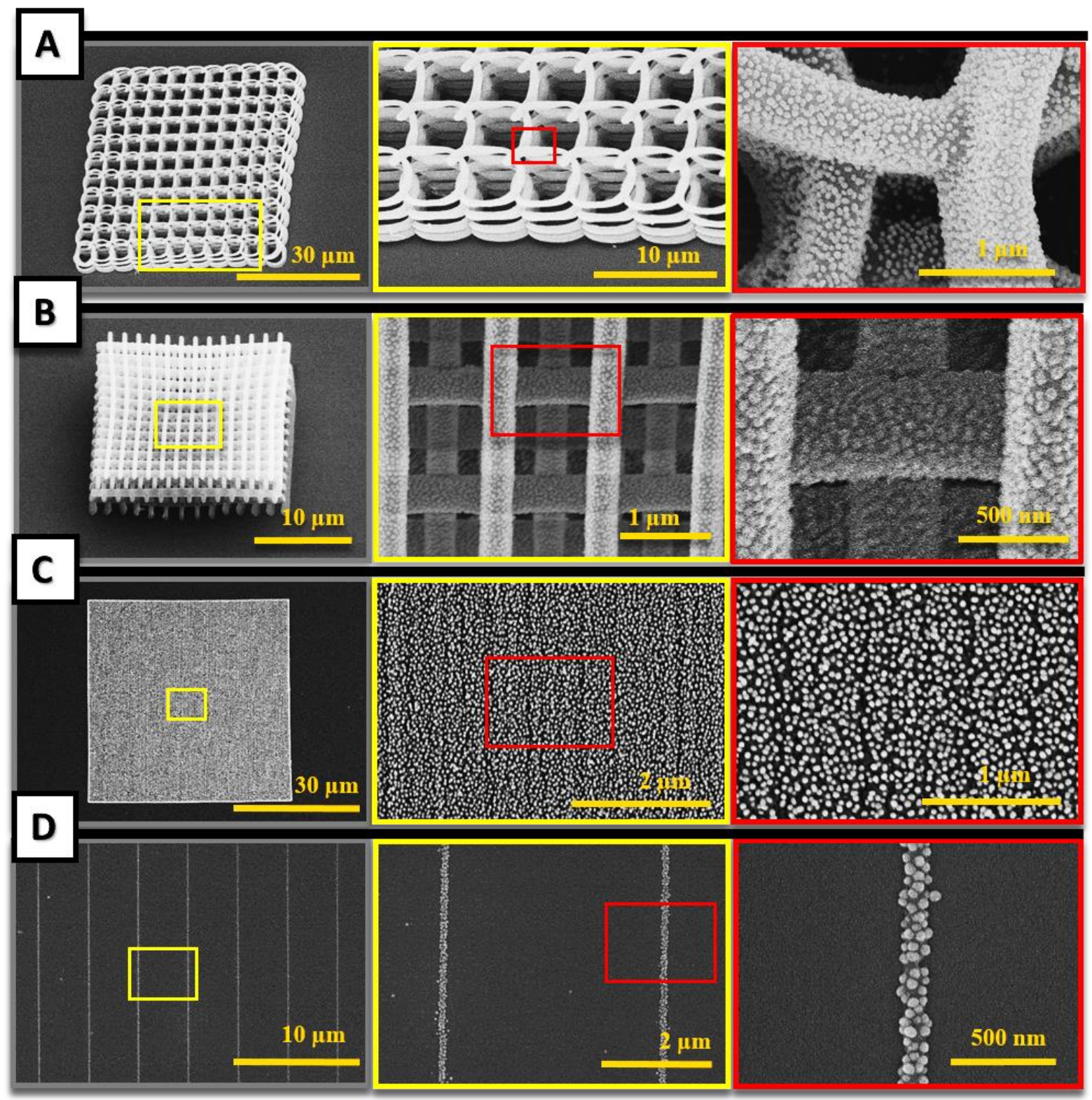

Figure 4. SEM images of GNPs immobilization on: 3D helices (A) and woodpiles (B); flat square microstructures (C) and continuous lines (D).

Besides the ability of immobilization on multiple dimension fabrications, using direct laser writing, it is also possible to control the gap size of the $3 \mathrm{D}$ microstructures, and thus the fabrication of different woodpiles with different periods (Figures 5-A, B, C and D) which is 
an important property for photonic crystal applications for instance. ${ }^{44}$ The interest of the obtained results is that the GNPs penetrate inside the woodpile porosities and are immobilized also on the inner layers (Figure 5-E) and even on the bottom layers (Figure 5-F). This demonstrates the homogeneity of the attachment through the whole 3D structure.
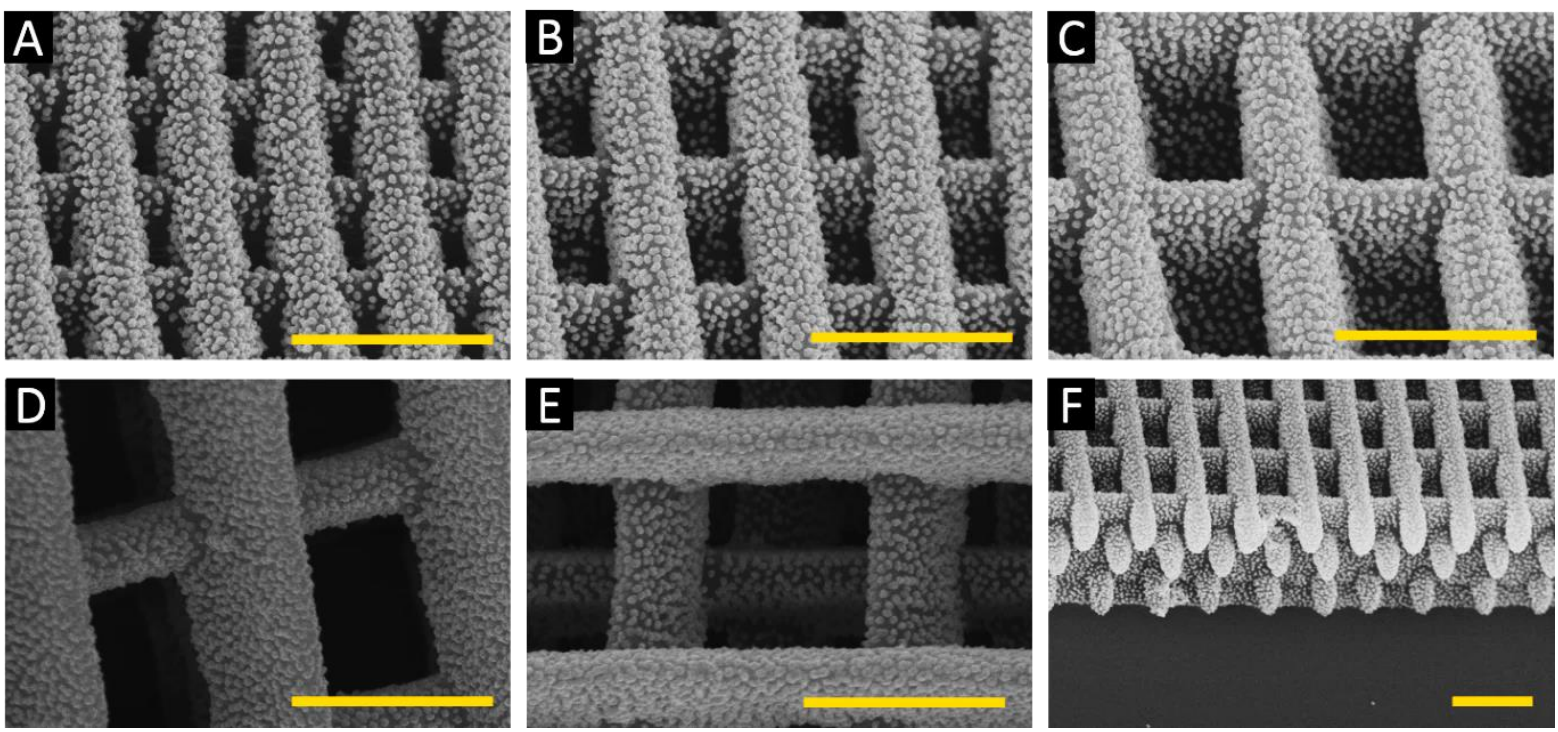

Figure 5. Woodpiles of different periods: 0.6 (A) 0.8 (B) $1.0(\mathbf{C})$ and $1.5 \mu \mathrm{m}(\mathbf{D})$; inner layers (E) and bottom layers (F) after immersion in GNPs colloid. Scale bar is $1 \mu \mathrm{m}$.

Moreover, it is possible to increase the number of NPs by adding more layers in the $\mathrm{Z}$ position for the woodpiles, as shown from the compared extinction spectra in Figure 6 between the 2D flat square and the woodpile structures with the same period but with more layers. As expected, the extinction spectra show a significant increase of both transverse and longitudinal plasmonic bands (535 and $680 \mathrm{~nm}$ ) with a red shift upon moving from 2D to 3D and an increase of the number of layers. The possibility to increase the quantity of NPs on different patterned structures is paramount for many applications like in sensing where high interaction with the target molecules is required. 

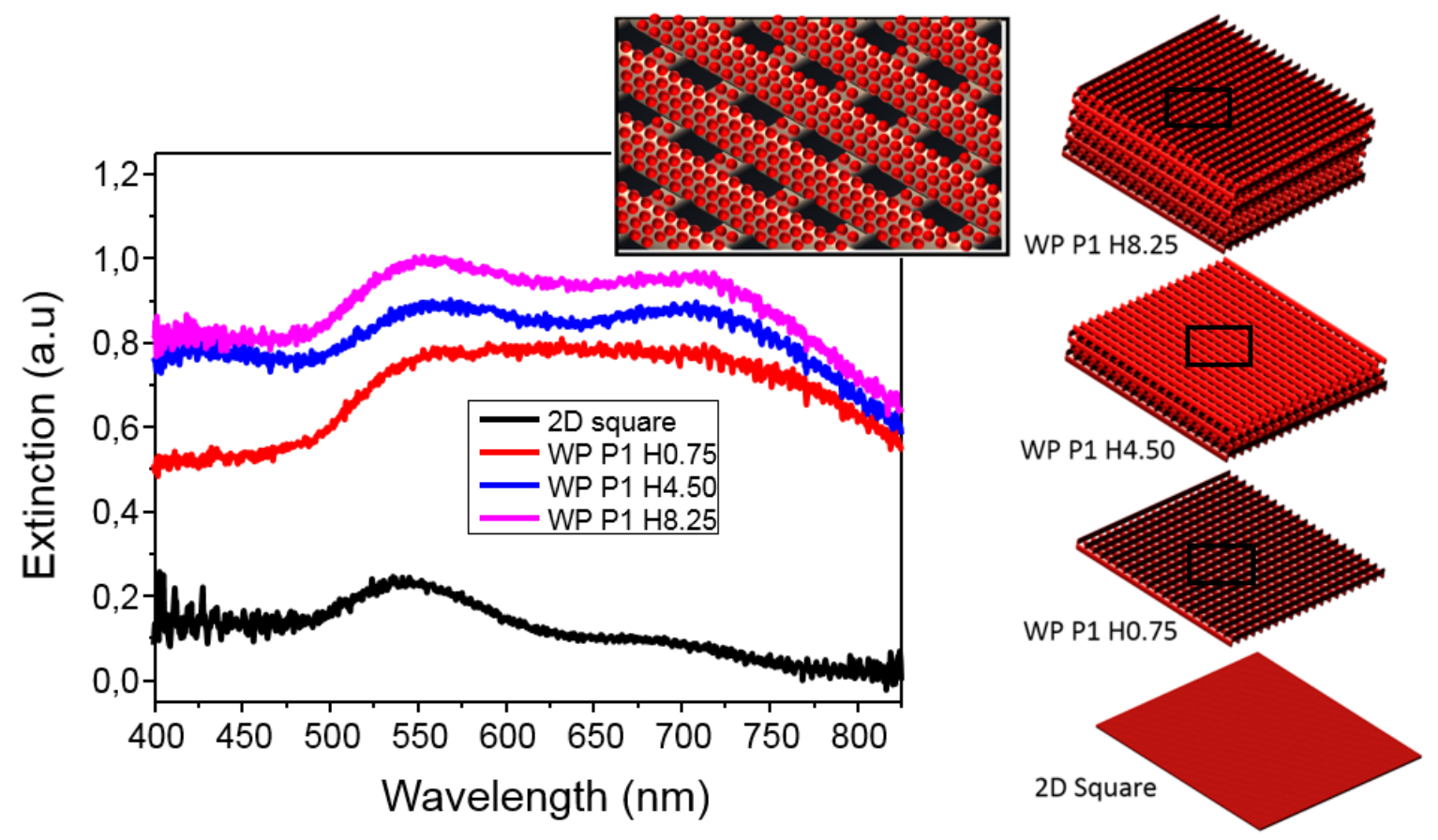

Figure 6. Illustration of $2 \mathrm{D}$ square and woodpile $(\mathrm{WP})$ structures of the same period $(\mathrm{P}=1)$ and different heights $(\mathrm{H}): 0.75,4.50$ and $8.25 \mu \mathrm{m}$ and their corresponding extinction spectra after fabrication and immersion in GNP solution.

Our functionalization process has allowed the possibility to incorporate NPs of different physical and chemical properties as long as they are negatively charged. Besides the GNPs immobilization, commercial polystyrene nanoparticles (PSNPs) spheres, stabilized by carboxylate ligands (average diameter $\approx 800 \mathrm{~nm}$ ) are 1 D-assembled along a polymer line as well as within a 3D polymer woodpile, illustrating the capability of this strategy to assemble NPs that have large diameters in this case, as shown in Figures 7-A, B and C. In addition, citrated silver nanoparticles (AgNPs) (average diameter $30 \sim 45 \mathrm{~nm}$ ) are successfully attached on polymer micro-square structures (Figure 7-D). The corresponding extinction spectrum shows an expected plasmonic peak $\left(\lambda_{\max }\right)$ around $416 \mathrm{~nm}$ (Figure 7-E). ${ }^{45} \mathrm{We}$ also demonstrated the possibility to attach magnetic NPs with our method using citrated iron oxide $\left(\mathrm{Fe}_{2} \mathrm{O}_{3}\right) \mathrm{NPs}$ (average diameter of $20 \sim 25 \mathrm{~nm}$ ) which are effectively immobilized on a functionalized micropolymer helix as shown in Figure 7-F. Moreover, nanodiamonds, which have potential 
application in quantum devices as single photon emitters, ${ }^{46}$ are introduced to the list of NPs used in this strategy. Figure 7-G clearly shows a single nanodiamond attached on a functionalized polymer dot. The possibility to assemble a wide range of NPs including dielectrics and metal oxides opens the door for new original microstructures and nanostructures for hybrid plasmonics, quantum technologies, biosensing, and drug delivery applications.
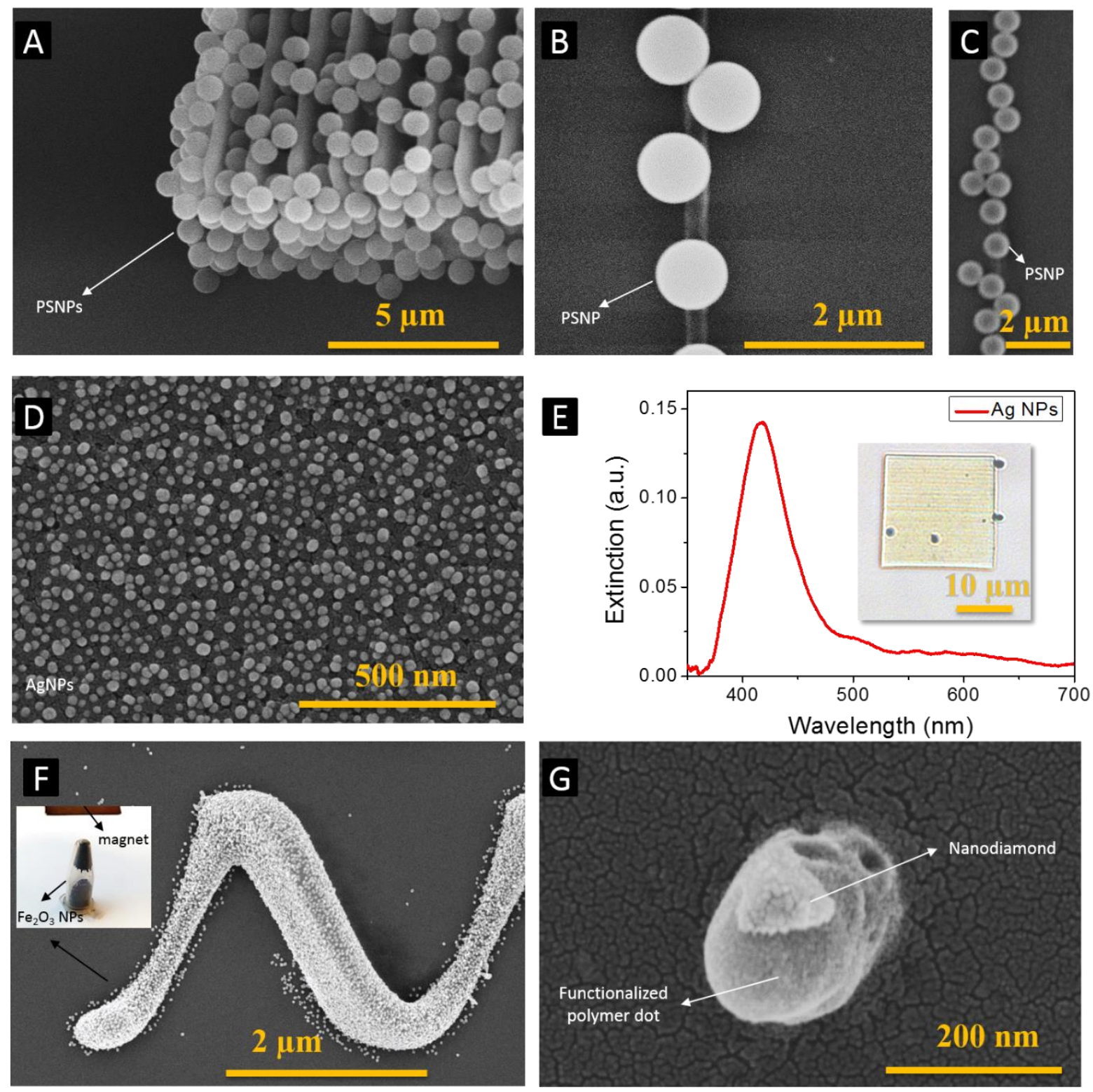

Figure 7. Carboxylated PS of $800 \mathrm{~nm}$ size on woodpile structure (A) and polymer lines (B\&C); AgNPs of $30 \sim 40 \mathrm{~nm}$ size on a $2 \mathrm{D}$ square polymer microstructure (D) and their extinction spectrum and optical microscope image (E). $\mathrm{Fe}_{2} \mathrm{O}_{3}$ NPs on a polymer helix with an image 
showing the attraction of the iron oxide NPs towards a magnet $(\mathbf{F})$. Nanodiamond attached on functionalized polymer dot (G).

In particular, the possibility to integrate and control the number of nano-emitters is a key element in the field of photonic and integrated quantum technologies. For this reason, the integration of fluorescent PSNPs and light emitting nanocrystals with a spatially controlled manner on functionalized polymer surfaces is investigated. Figures 8-I show the clear attachment of fluorescent PSNPs of size $\sim 50 \mathrm{~nm}$ on functionalized polymer dots. The emission spectrum in Figures 8-III at $\lambda=608 \mathrm{~nm}$ corresponds to the emission from many PSNPs attached on a functionalized polymer micro-dot (a) as well as a single PSNP on a very small and thin functionalized polymer dot (less than $50 \mathrm{~nm}$ ) (b). Excitation of the fluorescent PSNPs are done using a cw blue laser $(\lambda=405 \mathrm{~nm})$ using a home-made micro-photoluminescence ( $\mu \mathrm{PL}$ ) set-up capable of single photon detection. ${ }^{47}$ Figures 8-II show the successful attachment of carboxylated CdSe/ZnS red-emitting QDs (size $\sim 8 \mathrm{~nm}$, emission wavelength $\lambda=625 \mathrm{~nm}$ ) on functionalized polymer dots. It appears from the SEM images that QDs are selectively immobilized on the polymer dots of variable size while the background is completely clean which, considering the small sizes of QDs, is quite a feature. As can be seen in Figures 8-II, the number of QDs depends on the size of the polymer dots. The smallest polymer dot allowed us to obtain only 3 QDs immobilized. The ability to control the size of polymer dots by adjusting the laser power (LP) and exposure time (ET) during the polymerization process, allows us to control the number of PSNPs and QDs attached.

As the LP (from $10 \mathrm{~mW}$ to $5 \mathrm{~mW}$, by steps of $1 \mathrm{~mW}$ ) and ET (from $5 \mathrm{~ms}$ to $1 \mathrm{~ms}$, by steps of $1 \mathrm{~ms}$ ) decrease, we obtain smaller polymer dots and thus a decrease of the contact surface area with the NPs. Therefore, less NPs will be attached down to few NPs only (See Figures 8-I and II). 
For the QDs, photoluminescence was obtained by the excitation of a blue laser on a polymer micro-dot containing a big number of QDs and on 3 QDs attached on the smallest and thinnest polymer dot. The emission spectra are shown in Figure 8-IV. It appears from the SEM images and the emission spectra that the background is very clean and clear as no emission is recorded. Controlling the number of QDs and their positioning is a very important asset for nano-optics where the selective integration of nano-emitters with high spatial resolution on waveguides and on plasmonic devices is needed. ${ }^{47-49}$
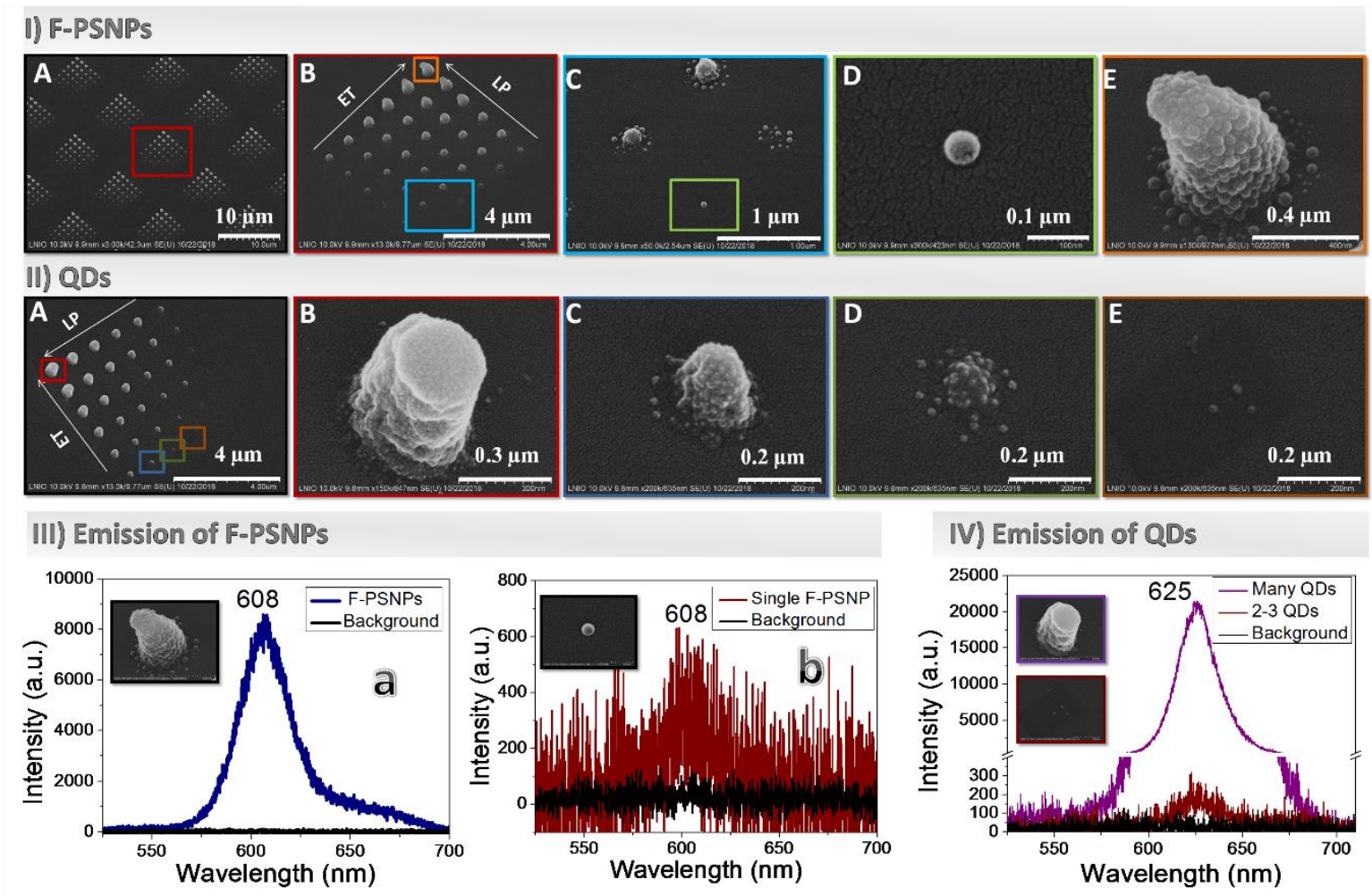

Figure 8. I) SEM images of patterns containing functionalized polymer dots after immersion in Fluorescent PSNPs (size $\sim 50 \mathrm{~nm}$ ) (A), magnification on one pattern corresponding to polymer dots obtained at different ET and LP (B), magnification on B (C, D and E). II) SEM image of one pattern of functionalized polymer dots, obtained at different ET and LP, after immersion in $\mathrm{CdSe} / \mathrm{ZnS}$ red-emitting QDs (A) magnification on A (B, C, D and E). III) Emission spectra of many fluorescent PSNPs attached on a polymer microdot excited by a blue laser (LP $2 \mu \mathrm{W} / 1$ second) (a) and a single fluorescent PSNP attached on a very small polymer 
dot (below $50 \mathrm{~nm}$ ) excited by a blue laser (LP $2 \mu \mathrm{W} / 2$ seconds) (b). IV) Emission spectra of many CdSe/ZnS red-emitting QDs attached on a polymer micro-dot excited by a blue laser (LP $2 \mu \mathrm{W} / 1$ second) (violet) and 3 QDs attached on a very small and thin polymer dot excited by a blue laser (LP $2 \mu \mathrm{W} / 10$ seconds) (brick red).

The ability to manipulate light at the nanoscale is one of the most important features in integrated photonic quantum technologies. However, conventional optical devices suffer from the diffraction limit of light. To overcome this limitation, plasmonic nanoantennas (PNAs) which are sensitive to light polarization, are introduced for the control of light direction at the nanoscale. When the PNAs are coupled to suitable nanoemitters, the hybrid nanosource emits light whose emission properties depend on the polarization state of the exciting beam. ${ }^{50}$ However, a major obstacle in this field is the precise integration of these nanoemitters on nanostructures and waveguides within well-controlled pattern shapes, which is currently a key issue in nano-optics. ${ }^{50}$ More precisely, for hybrid plasmonic nanosources of light acting as optical nanoswitch, the main challenge is to place the nanoemitter with a spatially controlled manner near the PNA, in order to obtain an efficient coupling at a certain polarization state of the exciting beam. In this context, Dandan Ge et al. ${ }^{47}$ succeeded to integrate QDs to PNAs by plasmon-triggered TPP in a photosensitive formulation containing QDs. These nanoemitters are embedded inside the polymer area that is locally printed thanks to the enhanced electromagnetic field located near the PNA. To improve this coupling, the number of QDs and their distance to the PNA have to be controlled. However, it is quite difficult to quantify the number of nanoemitters inside the polymer and their spatial distribution is completely random, as this distribution depends on their initial dispersion in the formulation and their possible migration during TPP. By using our approach for selective integration of NPs, a hybrid nanoplasmonic system is demonstrated here where QDs are immobilized on a functionalized 
nanopolymer surface in the close vicinity of a single gold nanocube (Figures 9-A \& B). The functionalized nanopolymer is first fabricated by plasmonic near-field polymerization, ${ }^{46,50,51}$ then is immersed in a colloidal solution of negatively charged CdSe/ZnS red-emitting QDs with emission wavelength at $\lambda=623 \mathrm{~nm}$ (See Figure S11). The obtained results in Figure 9 show a precise and selective attachment of QDs on the two corners of the gold nanocube where the functionalized polymer was printed by plasmon-induced polymerization (See supporting information Figures S12, S13, S14 and S15).

Compared to ref. 40, the novelty of this attachment near a single gold nanocube is the ability to control the distance between the PNA and the QDs through the size of the functionalized polymer. As the QDs are placed near the gold nanocube, their emission at $\lambda=623 \mathrm{~nm}$ will be enhanced by the localized surface plasmon resonance (LSPR). Therefore, the emission of QDs (Figures 9-C\&D) shows a high polarization sensitivity that is related to the tunable spatial overlap between the LSPR near-field of the nanocube and the QD distribution, ${ }^{46}$ which makes it very important for many applications such as optical nanoswitches. ${ }^{52}$ 

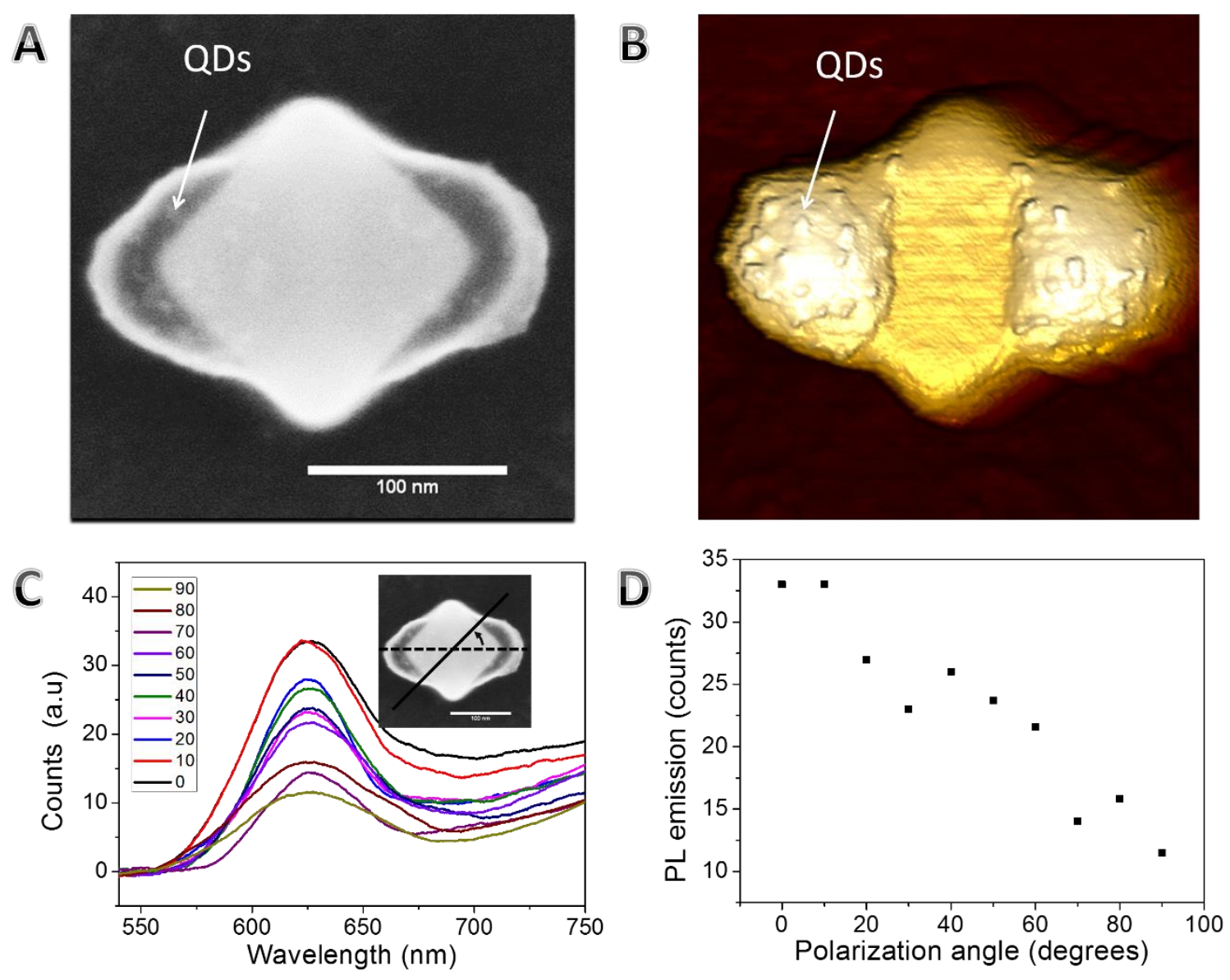

Figure 9. SEM (A) and AFM (B) images of $\mathrm{CdSe} / \mathrm{ZnS}$ red-emitting QDs attached on functionalized polymer at the two corners of a gold nanocube, and their emission spectra at different polarization angles (C). Photoluminescence emission intensity as a function of the polarization angle (D).

\section{CONCLUSION}

In conclusion, a general strategy is demonstrated to assemble NPs within 1D, 2D and 3D polymer micro and nanostructures. This new strategy is based on the chemical grafting of amine molecules into acrylate monomer according to Oxa Michael addition reaction on the PETA monomer followed by TPP fabrication of 1D, 2D and 3D polymer structures. These polymer structures are then immersed in a colloidal solution of various NPs (gold, silver, polystyrene, iron, quantum dots, nanodiamonds) and a high selectivity towards the $1 \mathrm{D}, 2 \mathrm{D}$ and $3 \mathrm{D}$ functionalized polymer surfaces is demonstrated. In particular, GNPs are assembled into 
polymer woodpiles with period ranging from 0.6 to $1.5 \mu \mathrm{m}$. This assembly results in the formation of monolayers of NPs with tunable coverage rate that can be adjusted by varying the immersion time and the type of amine molecule grafted on the polymer surface. Using this technique, assembly of PSNPs, Iron oxide NPs, nanodiamonds and QDs is demonstrated. QDs in hybrid nanoplasmonic systems were placed near plasmonic nanoantennas (gold nanocubes) as nanoemitters for an optical nanoswitch.

By using our strategy with controlling the size of the functionalized polymer area, precise integration of single QDs and nanodiamonds can be done near plasmonic nanoantennas, nanowires, metal gratings, plasmon functionalized optical waveguides ${ }^{47,48,53}$. This precise integration could be done by simply adjusting the polymer size, which offers the potential of controlling the number of QDs attached at the vicinity of the plasmonic nanoantenna, as well as the distance between them. Coupling these single nanoemitters with such photonic devices through our integration method will be an efficient manner to fabricate and control the properties of single photon sources in the near future. ${ }^{47}$

\section{METHODS AND MATERIALS}

Samples preparation: For TPP: 4.92 mmol of PETA monomer is functionalized by 2.51 mmol of Alkanoamine (in this study we used the methyldiethanol amine (MDEA) molecule), $0.07 \mathrm{mmol}$ of Irg-819 photoinitiator are added in order to initiate the polymerization process and $1.13 \mathrm{mmol}$ of monomethyl ether of hydroquinone (MEHQ) as an inhibitor are included to control the spatial resolution of the lithography process. The mixture is stirred for $45 \mathrm{~min}$ at 45 ${ }^{\circ} \mathrm{C}$. One drop from the prepared mixture is deposited on a glass substrate $(22 \times 22 \mathrm{~mm})$ to write the desired microstructure using Nanoscribe. After the accomplishing of the photopolymerization process, lift-off is done in acetone and isopropanol in order to remove the unpolymerized materials. The obtained samples are immersed for 5 hours in GNPs and AgNPs 
solutions, 3 hours in PSNPs, $\mathrm{Fe}_{2} \mathrm{O}_{3}$ NPs, nanodiamonds and QDs solutions, of acidic $\mathrm{pH}$ medium to allow the protonation of amines on the polymer surface and thus the assembly of negatively charged NPs on its surface by electrostatic interaction (see figure S16). For Plasmoninduced polymerization; $4.99 \mathrm{mmol}$ of PETA monomer was functionalized by $2.51 \mathrm{mmol}$ of MDEA, $0.039 \mathrm{mmol}$ of 2-Isopropylthioxanthone (ITX) photoinitiator and $1.13 \mathrm{mmol}$ of MEHQ inhibitor are added (See supporting information). The mixture is stirred for $45 \mathrm{~min}$ at $45{ }^{\circ} \mathrm{C}$. Then the sample is immersed in QDs solution for 30 min. PETA, MDEA, Irg-819 and MEHQ are purchased from Sigma Aldrich. ITX is purchased from Tokyo Chemical Industry.

Nanoparticles Synthesis: GNPs are prepared following the Turkevish's method described in the literature. ${ }^{54}$ AgNPs are prepared following the Lee-Meisel method. ${ }^{45} \mathrm{Fe}_{2} \mathrm{O}_{3}$ NPs are prepared following the procedure mentioned in Nigam's et al. article. ${ }^{48}$ The synthesized solutions are used directly for immersion process without any dilution. Commercial PSNPs solution (size $800 \mathrm{~nm}, 4 \%$ solid in $5 \mathrm{~mL} \mathrm{H}_{2} \mathrm{O}$ ) is diluted 500 times in water and nanodiamonds solution $\left(1 \mathrm{mg} / 1 \mathrm{~mL} \mathrm{H} \mathrm{H}_{2} \mathrm{O}\right)$ is diluted 100 times in water. Both are purchased from Sigma Aldrich. Carboxylated CdSe/ZnS red QDs solution $\left(10 \mathrm{mg} / 1 \mathrm{~mL} \mathrm{H}_{2} \mathrm{O}\right)$ is diluted 100 times in water and Fluorescent PSNPs solution $\left(5 \%\right.$ solid in $\left.1 \mathrm{~mL} \mathrm{H}_{2} \mathrm{O}\right)$ is diluted 100 times in water. They are purchased from Mesolight and Thermofisher respectively.

Instrumentation: The photopolymerization process is performed by Nanoscribe Photonic Professional system with a femtosecond laser at $\lambda=780 \mathrm{~nm}$ focused by a $100 \mathrm{x} / 1.3 \mathrm{NA}$ oil immersion objective. For Extinction spectra an optical microscope equipped with an upward configuration including a tungsten lamp and an optical fiber linked to a Maya 2000pro UVvisible detector. The acquisition was done in transmission mode using a 50 (NA: 0.8) objective. Under these conditions, the size of the collection area is less than $10 \mu \mathrm{m}$, which is quite smaller than the $50 \times 50 \mu \mathrm{m} 2$ of the micro-squares where the GNPs are immobilized. The optical set-up used to detect the PL of fluorescent PSNPs and QDs on polymer dots consists of a home-made 
confocal microscope with a $405 \mathrm{~nm}$ excitation wavelength from a $\mathrm{cw}$ laser. The incident laser beam is focused using a Nikon Plan $100 x$ objective of N.A=0.99. A long pass filter at $450 \mathrm{~nm}$ allows one to collect only the QD emission. A pinhole is used to select a specific detection area on the sample in order to collect the local PL. The PL measurements of QDs on gold nanocube at different polarization angles are measured by a spectrometer coupled to an inverted optical microscope (Olympus IX71), the whole optical configuration is indicated in figure S12. Optical microscopy images are taken on a Nikon Eclipse LV100 upright microscope. SEM images are obtained on a HITACHI S-3500 scanning electron microscope. AFM images are obtained by scanning the sample on Bruker's Dimension Icon Atomic Force Microscope (AFM) System using peak force tapping mode.

\section{AUTHOR INFORMATION}

\section{Corresponding Authors}

*E-mail: safi.jradi@utt.fr

\section{Author Contributions}

The manuscript was written through contributions of all authors. All authors have given approval to the final version of the manuscript.

\section{ACKNOWLEDGMENT}

Financial support of the "Conseil régional Grand Est", "EUR EIPHI Recherche", "FEDER" (Projets : Nanoassemblage 3D, Nano-intégration, Pronano et QLED), ANR (projet Active Nanophot), and NanoMat (www. nanomat.eu) by the "Ministère de l'enseignement supérieur et de la recherche" is acknowledged. 


\section{ABBREVIATIONS}

AFM Atomic Force Microscopy; AgNPs Silver Nanoparticles; ET Exposure Time; FTIR Fourier Transform Infra-Red; GNC Gold Nano Cube; GNPs Gold Nanoparticles; LSPR Localized Surface Plasmon Resonance; LP Laser Power; MNPs Metallic Nanoparticles; NPs Nanoparticles; PS PolyStyrene; PSNPs PolyStyrene Nanoparticles; PNA Plasmonic NanoAntennas; QDs Quantum Dots; SEM Scanning Electron Microscopy; TPP Two-Photon Polymerization.

\section{SUPPORTING INFORMATION}

Supporting Information Available: The supporting information includes data showing:

- An experimental evidence of the functionalization reaction of acrylic monomers following the Oxa Michael addition of methyl diethanolamine (MDEA) and Aza Michael addition of diethanolamine (DEA);

- The influence of amine used for functionalization on the density of Gold nanoparticles.

- $\quad$ Orange II Amine Test.

- $\quad$ Side view of woodpile functionalized polymer structure immobilized by GNPs.

- A detailed description of the approach of plasmon-induced polymerization and integration of QDs at the corners of a single GNC;

- $\quad$ The setup used for PL measurements of the hybrid system (GNC/polymer/QDs) under light excitation with different polarization angles;

- $\quad$ The influence of $\mathrm{pH}$ value of the colloidal solution on the density of GNPs. 
- Topography images by AFM of a GNC with and without polymer/QDs with their corresponding cross-sections.

This material is available free of charge via the Internet at http://pubs.acs.org.

\section{REFERENCES}

(1) Guerrero-Martínez, A.; Grzelczak, M.; Liz-Marzán, L. M. Molecular Thinking for Nanoplasmonic Design. ACS Nano 2012, $6 \quad$ (5), 3655-3662. https://doi.org/10.1021/nn301390s.

(2) Hamon, C.; Liz-Marzán, L. M. Hierarchical Assembly of Plasmonic Nanoparticles. Chem. - A Eur. J. 2015, 21 (28), 9956-9963. https://doi.org/10.1002/chem.201500149.

(3) Solis, D.; Paul, A.; Olson, J.; Slaughter, L. S.; Swanglap, P.; Chang, W.-S.; Link, S. Turning the Corner: Efficient Energy Transfer in Bent Plasmonic Nanoparticle Chain Waveguides. Nano Lett. 2013, 13 (10), 4779-4784. https://doi.org/10.1021/nl402358h.

(4) Li, M.; Zhang, H.; Zhang, J.; Wang, C.; Han, K.; Yang, B. Easy Preparation and Characterization of Highly Fluorescent Polymer Composite Microspheres from Aqueous CdTe Nanocrystals. J. Colloid Interface Sci. 2006, 300 (2), 564-568. https://doi.org/10.1016/j.jcis.2006.04.031.

(5) Kubo, S.; Gu, Z.-Z.; Tryk, D. A.; Ohko, Y.; Sato, O.; Fujishima, A. Metal-Coated Colloidal Crystal Film as Surface-Enhanced Raman Scattering Substrate. Langmuir 2002, 18 (13), 5043-5046. https://doi.org/10.1021/la020176+.

(6) Chehadi, Z.; Alkees, N.; Bruyant, A.; Toufaily, J.; Girardon, J.-S.; Capron, M.; Dumeignil, F.; Hamieh, T.; Bachelot, R.; Jradi, S. Plasmonic Enhanced Photocatalytic Activity of Semiconductors for the Degradation of Organic Pollutants under Visible 
Light. Mater. Sci. Semicond. Process. 2016, 42, 81-84. https://doi.org/10.1016/j.mssp.2015.08.044.

(7) Lee, J.-H.; Kim, D. O.; Song, G.-S.; Lee, Y.; Jung, S.-B.; Nam, J.-D. Direct Metallization of Gold Nanoparticles on a Polystyrene Bead Surface Using Cationic Gold Ligands. Macromol. Rapid Commun. 2007, $28 \quad$ (5), 634-640. https://doi.org/10.1002/marc.200600757.

(8) Hirsch, L. R.; Gobin, A. M.; Lowery, A. R.; Tam, F.; Drezek, R. A.; Halas, N. J.; West, J. L. Metal Nanoshells. Ann. Biomed. Eng. 2006, 34 (1), 15-22. https://doi.org/10.1007/s10439-005-9001-8.

(9) Aroca, R. Surface Enhanced Vibrational Spectroscopy; Wiley, 2006.

(10) Akil-Jradi, S.; Jradi, S.; Plain, J.; Adam, P.-M.; Bijeon, J.-L.; Royer, P.; Bachelot, R. Micro/Nanoporous Polymer Chips as Templates for Highly Sensitive SERS Sensors. RSC Adv. 2012, 2 (20), 7837. https://doi.org/10.1039/c2ra21186f.

(11) Izquierdo-Lorenzo, I.; Jradi, S.; Adam, P.-M. Direct Laser Writing of Random Au Nanoparticle Three-Dimensional Structures for Highly Reproducible Micro-SERS Measurements. RSC Adv. 2014, 4 (8), 4128-4133. https://doi.org/10.1039/C3RA46220J.

(12) Shamsaie, A.; Heim, J.; Yanik, A. A.; Irudayaraj, J. Intracellular Quantification by Surface Enhanced Raman Spectroscopy. Chem. Phys. Lett. 2008, 461 (1), 131-135. https://doi.org/10.1016/j.cplett.2008.06.064.

(13) Viste, P.; Plain, J.; Jaffiol, R.; Vial, A.; Adam, P. M.; Royer, P. Enhancement and Quenching Regimes in Metal-Semiconductor Hybrid Optical Nanosources. In ACS Nano; American Chemical Society, 2010; 4, 759-764. https://doi.org/10.1021/nn901294d.

(14) Biju, V.; Itoh, T.; Anas, A.; Sujith, A.; Ishikawa, M. Semiconductor Quantum Dots and Metal Nanoparticles: Syntheses, Optical Properties, and Biological Applications. Anal. 
Bioanal. Chem. 2008, 391 (7), 2469-2495. https://doi.org/10.1007/s00216-008-2185-7.

(15) Cui, L.; Li, C. C.; Tang, B.; Zhang, C. Y. Advances in the Integration of Quantum Dots with Various Nanomaterials for Biomedical and Environmental Applications. Analyst 2018, 143 (11), 2469-2478. https://doi.org/10.1039/c8an00222c.

(16) Pandey, S.; Bodas, D. High-Quality Quantum Dots for Multiplexed Bioimaging: A Critical Review. Advances in Colloid and Interface Science. Elsevier B.V. April 1, 2020, p 102137. https://doi.org/10.1016/j.cis.2020.102137.

(17) Elsinger, L.; Gourgues, R.; Zadeh, I. E.; Maes, J.; Guardiani, A.; Bulgarini, G.; Pereira, S. F.; Dorenbos, S. N.; Zwiller, V.; Hens, Z.; Van Thourhout, D. Integration of Colloidal $\mathrm{PbS} / \mathrm{CdS}$ Quantum Dots with Plasmonic Antennas and Superconducting Detectors on a Silicon Nitride Photonic Platform. Nano Lett. 2019, 19 (8), 5452-5458. https://doi.org/10.1021/acs.nanolett.9b01948.

(18) Mikrajuddin, F.; Iskandar, F.; Okuyama, K. Single Route for Producing Organized Metallic Domes, Dots, and Pores by Colloidal Templating and Over-Sputtering. $A d v$. Mater. 2002, $14 \quad$ (12), $\quad 930 . \quad$ https://doi.org/10.1002/15214095(20020618)14:12<930::AID-ADMA930>3.0.CO;2-L.

(19) Cui, Y.; Björk, M. T.; Liddle, J. A.; Sönnichsen, C.; Benjamin Boussert, A.; Alivisatos, A. P. Integration of Colloidal Nanocrystals into Lithographically Patterned Devices. Nano Lett. 2004, 4 (6), 1093-1098. https://doi.org/10.1021/NL049488I.

(20) Gates, B. D.; Xu, Q.; Stewart, M.; Ryan, D.; C. Grant Willson, A.; Whitesides, G. M. New Approaches to Nanofabrication: Molding, Printing, and Other Techniques. Chem. Rev. 2005, 105 (4), 1171-1196. https://doi.org/10.1021/CR030076O.

(21) Flauraud, V.; Mastrangeli, M.; Bernasconi, G. D.; Butet, J.; Alexander, D. T. L.; Shahrabi, E.; Martin, O. J. F.; Brugger, J. Nanoscale Topographical Control of Capillary Assembly of Nanoparticles. Nat. Nanotechnol. 2017, 12 (1), 73-80. 
https://doi.org/10.1038/nnano.2016.179.

(22) Su, B.; Zhang, C.; Chen, S.; Zhang, X.; Chen, L.; Wu, Y.; Nie, Y.; Kan, X.; Song, Y.; Jiang, L. A General Strategy for Assembling Nanoparticles in One Dimension. $A d v$. Mater. 2014, 26 (16), 2501-2507. https://doi.org/10.1002/adma.201305249.

(23) Jägeler-Hoheisel, T.; Cordeiro, J.; Lecarme, O.; Cuche, A.; Girard, C.; Dujardin, E.; Peyrade, D.; Arbouet, A. Plasmonic Shaping in Gold Nanoparticle Three-Dimensional Assemblies. J. Phys. Chem. C 2013, 117 (44), 23126-23132. https://doi.org/10.1021/jp406410k.

(24) Noriki, T.; Abe, S.; Kajikawa, K.; Shimojo, M. Patterning Technique for Gold Nanoparticles on Substrates Using a Focused Electron Beam. Beilstein J. Nanotechnol. 2015, 6 (1), 1010-1015. https://doi.org/10.3762/bjnano.6.104.

(25) Zhang, B.; Meng, F.; Feng, J.; Wang, J.; Wu, Y.; Jiang, L. Manipulation of Colloidal Particles in Three Dimensions via Microfluid Engineering. Adv. Mater. 2018, 30 (22), 1-8. https://doi.org/10.1002/adma.201707291.

(26) Zhang, J.; Yang, B. Patterning Colloidal Crystals and Nanostructure Arrays by Soft Lithography. Adv. Funct. Mater. 2010, $20 \quad$ (20), 3411-3424. https://doi.org/10.1002/adfm.201000795.

(27) Wang, B.; Li, B.; Ferrier, R. C. M.; Li, C. Y. Polymer Single Crystal Templated Janus Nanoparticles. Macromol. Rapid Commun. 2010, $31 \quad$ (2), 169-175. https://doi.org/10.1002/marc.200900735.

(28) Xiao, C. W.; Chi, L. F.; Fuchs, H. Patterning of Semiconductor Nanoparticles via Microcontact Printing. Eur. J. Inorg. Chem. 2005, No. 18, 3729-3733. https://doi.org/10.1002/ejic.200500520.

(29) Wang, Y.; Fedin, I.; Zhang, H.; Talapin, D. V. Direct Optical Lithography of Functional Inorganic Nanomaterials. Science. 2017, $357 \quad$ (6349), 385-388. 
https://doi.org/10.1126/science.aan2958.

(30) Hellstrom, S. L.; Kim, Y.; Fakonas, J. S.; Senesi, A. J.; Macfarlane, R. J.; Mirkin, C. A.; Atwater, H. A. Epitaxial Growth of DNA-Assembled Nanoparticle Superlattices on Patterned Substrates. Nano Lett. 2013, $13 \quad$ (12), 6084-6090. https://doi.org/10.1021/n14033654.

(31) Sun, L.; Lin, H.; Li, Y.; Zhou, W.; Du, J. S.; Mirkin, C. A. Position- and OrientationControlled Growth of Wulff-Shaped Colloidal Crystals Engineered with DNA. Adv. Mater. 2020, 32 (47), 2005316. https://doi.org/10.1002/adma.202005316.

(32) Zhang, H.; Cadusch, J.; Kinnear, C.; James, T.; Roberts, A.; Mulvaney, P. Direct Assembly of Large Area Nanoparticle Arrays. ACS Nano 2018, 12 (8), 7529-7537. https://doi.org/10.1021/acsnano.8b02932.

(33) Pekdemir, S.; Torun, I.; Sakir, M.; Ruzi, M.; Rogers, J. A.; Onses, M. S. Chemical Funneling of Colloidal Gold Nanoparticles on Printed Arrays of End-Grafted Polymers for Plasmonic Applications. ACS Nano 2020, $14 \quad$ (7), 8276-8286. https://doi.org/10.1021/acsnano.0c01987.

(34) Nising, C. F.; Bräse, S. Recent Developments in the Field of Oxa-Michael Reactions. Chem. Soc. Rev. 2012, 41 (3), 988-999. https://doi.org/10.1039/C1CS15167C.

(35) Ying, A.-G.; Liu, L.; Wu, G.-F.; Chen, G.; Chen, X.-Z.; Ye, W.-D. Aza-Michael Addition of Aliphatic or Aromatic Amines to $\alpha, \beta$-Unsaturated Compounds Catalyzed by a DBU-Derived Ionic Liquid under Solvent-Free Conditions. Tetrahedron Lett. 2009, 50 (14), 1653-1657. https://doi.org/10.1016/J.TETLET.2009.01.123.

(36) Colantoni, D.; Fioravanti, S.; Pellacani, L.; Tardella, P. A. Aza-Michael Addition of Nosyloxycarbamates to 2-(Trifluoromethyl)Acrylates. Org. Lett. 2004, 6 (2), 197-200. https://doi.org/10.1021/o10361554.

(37) Desmet, G. B.; D’hooge, D. R.; Omurtag, P. S.; Espeel, P.; Marin, G. B.; Du Prez, F. E.; 
Reyniers, M.-F. Quantitative First-Principles Kinetic Modeling of the Aza-Michael Addition to Acrylates in Polar Aprotic Solvents. J. Org. Chem. 2016, 81 (24), 1229112302. https://doi.org/10.1021/acs.joc.6b02218.

(38) Yee, D. W.; Schulz, M. D.; Grubbs, R. H.; Greer, J. R. Functionalized 3D Architected Materials via Thiol-Michael Addition and Two-Photon Lithography. Adv. Mater. 2017, 29 (16). https://doi.org/10.1002/adma.201605293.

(39) LaFratta, C. N.; Fourkas, J. T.; Baldacchini, T.; Farrer, R. A. Multiphoton Fabrication. Angewandte Chemie - International Edition. John Wiley \& Sons, Ltd August 20, 2007, 6238-6258. https://doi.org/10.1002/anie.200603995.

(40) Lay, C. L.; Koh, C. S. L.; Lee, Y. H.; Phan-Quang, G. C.; Sim, H. Y. F.; Leong, S. X.; Han, X.; Phang, I. Y.; Ling, X. Y. Two-Photon-Assisted Polymerization and Reduction: Emerging Formulations and Applications. ACS Appl. Mater. Interfaces 2020, 12 (9), 10061-10079. https://doi.org/10.1021/acsami.9b20911.

(41) Pang, L.; Shen, Y.; Tetz, K.; Fainman, Y. PMMA Quantum Dots Composites Fabricated via Use of Pre-Polymerization. Opt. Express 2005, 13 (1), 44. https://doi.org/10.1364/opex.13.000044.

(42) Passinger, S.; Saifullah, M. S. M.; Reinhardt, C.; Subramanian, K. R. V.; Chichkov, B. N.; Welland, M. E. Direct 3D Patterning of TiO2 Using Femtosecond Laser Pulses. Adv. Mater. 2007, 19 (9), 1218-1221. https://doi.org/10.1002/adma.200602264.

(43) Klein, F.; Striebel, T.; Fischer, J.; Jiang, Z.; Franz, C. M.; von Freymann, G.; Wegener, M.; Bastmeyer, M. Elastic Fully Three-Dimensional Microstructure Scaffolds for Cell Force Measurements. Adv. Mater. 2010, $22 \quad$ (8), 868-871. https://doi.org/10.1002/adma.200902515.

(44) Deubel, M.; von Freymann, G.; Wegener, M.; Pereira, S.; Busch, K.; Soukoulis, C. M. Direct Laser Writing of Three-Dimensional Photonic-Crystal Templates for 
Telecommunications. Nat. Mater. 2004, $3 \quad$ (7), 444-447. https://doi.org/10.1038/nmat1155.

(45) Wan, Y.; Guo, Z.; Jiang, X.; Fang, K.; Lu, X.; Zhang, Y.; Gu, N. Quasi-Spherical Silver Nanoparticles: Aqueous Synthesis and Size Control by the Seed-Mediated Lee-Meisel Method. J. Colloid Interface Sci. 2013, 394, 263-268. https://doi.org/10.1016/j.jcis.2012.12.037.

(46) Schröder, T.; Gädeke, F.; Banholzer, M. J.; Benson, O. Ultrabright and Efficient SinglePhoton Generation Based on Nitrogen-Vacancy Centres in Nanodiamonds on a Solid Immersion Lens. New J. Phys. 2011, 13 (5), 055017. https://doi.org/10.1088/13672630/13/5/055017.

(47) Ge, D.; Marguet, S.; Issa, A.; Jradi, S.; Nguyen, T. H.; Nahra, M.; Béal, J.; Deturche, R.; Chen, H.; Blaize, S.; Plain, J.; Fiorini, C.; Douillard, L.; Soppera, O.; Dinh, X. Q.; Dang, C.; Yang, X.; Xu, T.; Wei, B.; Sun, X. W.; Couteau, C.; Bachelot, R. Hybrid Plasmonic Nano-Emitters with Controlled Single Quantum Emitter Positioning on the Local Excitation Field. Nat. Commun. 2020, 11 (1), 3414. https://doi.org/10.1038/s41467-020$17248-8$

(48) Xu, X.; Broussier, A.; Nahra, M.; Geoffray, F.; Issa, A.; Bachelot, R.; Couteau, C.; Blaize, S.; Ritacco, T. Towards the Integration of Nanoemitters by Direct Laser Writing on Optical Glass Waveguides. 2020.

(49) Lio, G. E.; Madrigal, J. B.; Xu, X.; Peng, Y.; Pierini, S.; Couteau, C.; Jradi, S.; Bachelot, R.; Caputo, R.; Blaize, S. Integration of Nanoemitters onto Photonic Structures by Guided Evanescent-Wave Nano-Photopolymerization. J. Phys. Chem. C 2019, 123 (23), 14669-14676. https://doi.org/10.1021/acs.jpcc.9b03716.

(50) Shields, A. J. Review: Semiconductor Quantum Light Sources. Nat. Photonics 2007, 1 (215). https://doi.org/10.1038/nphoton.2007.46. 
(51) Wang, Y.; Wang, S.; Zhang, S.; Scherman, O. A.; Baumberg, J. J.; Ding, T.; Xu, H. Plasmon-Directed Polymerization: Regulating Polymer Growth with Light. Nano Res. 2018, 11 (12), 6384-6390. https://doi.org/10.1007/s12274-018-2163-0.

(52) Nakamura, H.; Sugimoto, Y.; Asakawa, K. Ultra-Fast Photonic Crystal/Quantum Dot All-Optical Switch for Future Photonic Networks. Conf. Lasers Electro-Optics 2006 Quantum Electron. Laser Sci. Conf. CLEO/QELS 2006 2006, 12 (26), 6606-6614. https://doi.org/10.1109/CLEO.2006.4628030.

(53) Broussier, A.; Issa, A.; Le Cunff, L. O.; Nguyen, T. H.; Dinh, X. Q.; Blaize, S.; Plain, J.; Jradi, S.; Couteau, C.; Bachelot, R. Hybrid Plasmonic Nanosystem with Controlled Position of Nanoemitters. Appl. Phys. Lett. 2019, 114 (16), 163106. https://doi.org/10.1063/1.5093360.

(54) Frens, G. Controlled Nucleation for the Regulation of the Particle Size in Monodisperse $\begin{array}{llllll}\text { Gold } & \text { Suspensions. } & \text { Nature } & \text { 1973, } & 241 & \text { (105), }\end{array}$ https://doi.org/10.1038/10.1038/physci241020a0. 
TABLE OF CONTENT

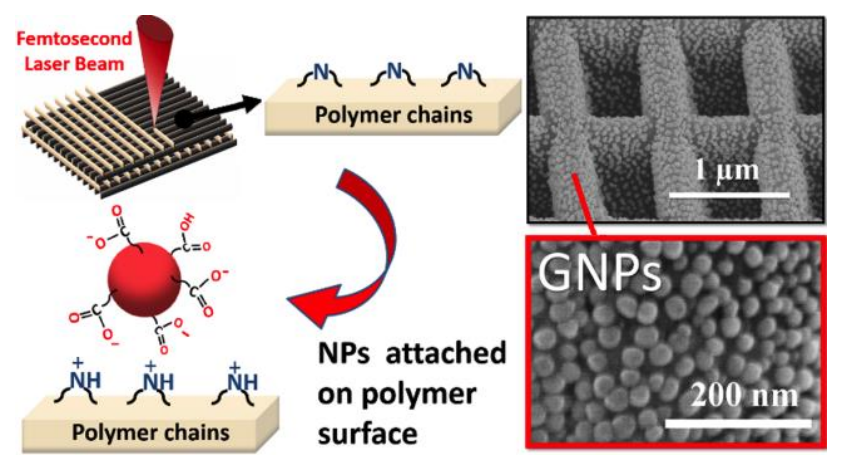

